Provided for non-commercial research and education use. Not for reproduction, distribution or commercial use.

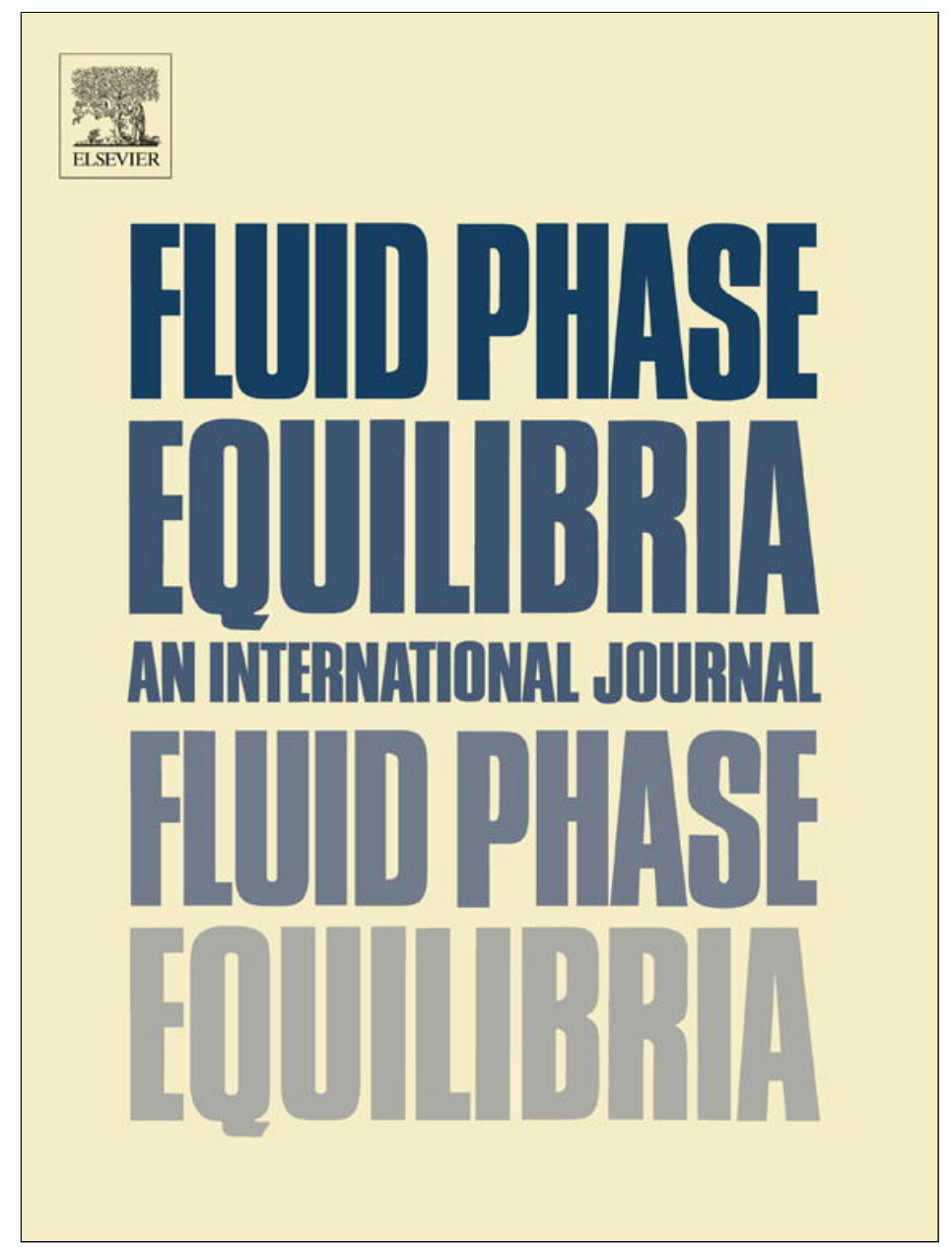

(This is a sample cover image for this issue. The actual cover is not yet available at this time.)

This article appeared in a journal published by Elsevier. The attached copy is furnished to the author for internal non-commercial research and education use, including for instruction at the authors institution and sharing with colleagues.

Other uses, including reproduction and distribution, or selling or licensing copies, or posting to personal, institutional or third party websites are prohibited.

In most cases authors are permitted to post their version of the article (e.g. in Word or Tex form) to their personal website or institutional repository. Authors requiring further information regarding Elsevier's archiving and manuscript policies are encouraged to visit:

http://www.elsevier.com/copyright 


\title{
Measurement and modeling of epicatechin solubility in supercritical carbon dioxide fluid
}

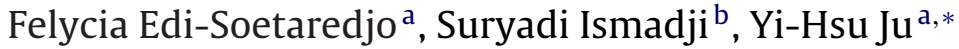 \\ a Department of Chemical Engineering, National Taiwan University of Science and Technology, 43, Sec. 4. Keelung Rd., Taipei, Taiwan \\ ${ }^{\mathrm{b}}$ Department of Chemical Engineering, Widya Mandala Surabaya Catholic University, Kalijudan 37, Surabaya 60114, Indonesia
}

\section{A R T I C L E I N F O}

\section{Article history:}

Received 4 August 2012

Received in revised form 20 October 2012

Accepted 6 December 2012

Available online 20 December 2012

\section{Keywords:}

Density based model

Epicatechin

Solubility

Supercritical carbon dioxide

\begin{abstract}
A B S T R A C T
The experimental equilibrium solubility of epicatechin in supercritical carbon dioxide was measured at several temperatures $(313.15,323.15,333.15$ and $343.15 \mathrm{~K})$ and pressure in the range of $12-26 \mathrm{MPa}$. The solubilities of epicatechin in supercritical $\mathrm{CO}_{2}$ increased with pressure and temperature. The effect of increasing temperature on the solubility is more significant at high pressure than low pressure. The experimental data were fitted very well by three density-based models of Chrastil, del Valle and Aguilera and the model of Méndez-Santiago and Teja. Reasonable fitting parameters of the models were obtained.
\end{abstract}

(C) 2012 Elsevier B.V. All rights reserved.

\section{Introduction}

Epicatechin ((-)-cis-3,3', 4',5,7-pentahydroxyflavane $(2 R, 3 R)-2-$ (3,4-dihydroxyphenyl)-3,4-dihydro-1(2H)-benzopyran-3,5,7-tri$\mathrm{ol}$ ) is a flavonol belonging to the group of flavonoids and widely present in fruits and vegetables. High quantities of epicatechin can be found in cocoa [1], tea [2-4] and grapes [5-7]. Epicatechin is also found in staple plant such as sago (Metroxylon sago) [8]. Epicatechin exerts beneficial health-related effects since it acts as free radical scavengers and inhibitors of eicosainoid biosynthesis $[9,10]$. Epicatechin also reduces low-density lipoprotein in oxidation, risk of stroke, heart failure, cancer and diabetes $[1,9,11,12]$.

The initial step in the recovery and purification of flavonoids from plant materials is extraction. Soxhlet extractions using organic-aqueous solvents are commonly used; however this method is time consuming and uses a lot of organic solvents. Recently, microwave-assisted extraction [13], accelerated solvent extraction $[14,15]$ and supercritical fluid extraction were employed to obtain better recoveries and to reduce extraction time [16,17]. Among these extraction methods, supercritical fluid extraction (SFE) offers an environmental friendly choice in terms of using less amount of organic solvent. SFE works in the absence of light and air that cause degradation of flavonoids. Among many supercritical fluids, carbon dioxide is extremely attractive because of it

\footnotetext{
* Corresponding author. Tel.: +88622737 6611; fax: +886227376644.

E-mail address: yhju@mail.ntust.edu.tw (Y.-H. Ju).
}

has relatively low critical temperature ( $304.15 \mathrm{~K})$, is less possible to cause degradation of thermally labile compounds and is easily separable from the extracted solutes. Other benefits in using supercritical carbon dioxide $\left(\mathrm{SC} \mathrm{CO}_{2}\right)$ are it is nontoxic, nonflammables and inexpensive.

Process design based on SFE and the determination of optimum operating conditions require knowledge of phase equilibria and compound solubility in a supercritical fluid. In the last two decades, many attempts have been reported on the solubility of flavonoid compounds. Song et al. [18] determined the solubility of epigallocatechin gallate in $\mathrm{SC} \mathrm{CO}_{2}$ with ethanol cosolvent ( 0.044 and 0.084 mole fraction) at a temperature ranging from 313 to $333 \mathrm{~K}$ and pressure from 15 to $35 \mathrm{MPa}$. Their solubility data were correlated using a thermodynamic model, a modified Chrastil model and the Méndez-Santiago and Teja [19] model. Cháfer et al. [20] reported experimental measurements and thermodynamic modeling of the solubility of quercetin with ethanol as the cosolvent $(5-30 \%)$ at $313.15 \mathrm{~K}$ and pressure ranging from 8 to $12 \mathrm{MPa}$. The same operating conditions were used by Berna et al. [21] for catechin and Cháfer et al. [22] for epicatechin and the data were modeled using equations of state (EOS): Peng-Robinson and Soave-Redlich-Kwong models. Other solubility data of hydroxycinnamic acids in $\mathrm{SC} \mathrm{CO}_{2}$ were reported for 4-hydroxycinnamic acid ( $p$-coumaric acid), 3,4-dihydroxycinnamic acid (caffeic acid), 4-hydroxy-3-methoxycinnamic acid (ferulic acid) [23-25].

The existing solubility data for epicatechin in $\mathrm{SC} \mathrm{CO}_{2}+$ ethanol [22] was limited at one fixed temperature $(313 \mathrm{~K})$ and a narrow pressure range of 8-12 MPa. Wider ranges of temperature and pressure are essential in order to determine optimum operating 
conditions for separation of epicatechin from plant materials using $\mathrm{SC} \mathrm{CO}_{2}$. Epicatechin is almost insoluble in $\mathrm{SC} \mathrm{CO}_{2}$ due to its strong polarity; therefore ethanol is the best choice as cosolvent especially for food and pharmaceutical applications. In their report, Cháfer et al. [22] used ethanol as cosolvent in the range of 5-30\%. The presence of high amount of ethanol in their system may have changed the supercritical condition of $\mathrm{CO}_{2}$ into subcritical [26-29]. Joung et al. [29] found that the maximum concentration of ethanol in the system should be $6.49 \mathrm{~mol} \%$ at $8.15 \mathrm{MPa}$ and $313.15 \mathrm{~K}$ in order to obtain supercritical condition. Under subcritical condition, most epicatechin dissolved in ethanol rather than in $\mathrm{SC} \mathrm{CO}_{2}$. Further separation of epicatechin from ethanol is needed in order to obtain pure epicatechin.

Considering the importance of solubility data of solids in supercritical fluids for the developing of the extraction process and the dependency of solubility on density, temperature and pressure of supercritical fluids; extensive amounts of data are needed. Moreover, the present of cosolvent in $\mathrm{SC} \mathrm{CO}_{2}$ extraction produces impure extract with the cosolvent as an impurity. Therefore, in order to obtain pure extract, separation of extract and cosolvent is needed. The objective of this paper is to measure the solubilities of epicatechin in $\mathrm{SC} \mathrm{CO}_{2}$ without cosolvent at different temperatures $(313.15,323.15,333.15$, and $343.15 \mathrm{~K})$ and pressures $(12-26 \mathrm{MPa})$. The experimental data were then correlated using density-based models (Chrastil [30], del Valle and Aguilera [31] and MéndezSantiago and Teja [19] models). To the best of knowledge, there is no literature available on the solubility of epicatechin in $\mathrm{SC} \mathrm{CO}_{2}$ in the range of pressures and temperatures studied in this work.

\section{Experimental}

\subsection{Materials}

HPLC grade (-)-epicatechin with a purity of 98 wt.\% was obtained from Sigma-Aldrich (Singapore) and was used without any further purification. Analytical grade ethanol was supplied by Merck (Darmstadt, Germany) and was used as a solvent to collect extract for further analysis. Food grade carbon dioxide (99\% purity) was used as the supercritical solvent and supplied as liquid $\mathrm{CO}_{2}$ by Aneka Gas Pty Ltd (Indonesia) with a purity of 99.9\%.

\subsection{Experimental procedure}

The experiments of epicatechin solubility in supercritical $\mathrm{CO}_{2}$ were carried out in a static system consists of a $50 \mathrm{ml}$ long equilibration column (Swagelok, USA), a high pressure pump (Eldex AA-100-S-2-CE, USA) and a pressure transducer (Druck PTX 611, USA) with a digital process indicator (Druck DPI 280, USA) which gives a pressure measurement uncertainty of $\pm 0.01 \mathrm{MPa}$. The system temperature was controlled by a heating chamber (Oven Memmert, Germany). The uncertainty of temperature measurement in the heating chamber is $\pm 1 \mathrm{~K}$. All fitting and tubing used in this system were made of stainless steel 316 (Swagelok, USA). The maximum working pressure and temperature of the supercritical extraction system were $40 \mathrm{MPa}$ and $373.15 \mathrm{~K}$, respectively.

Epicatechin solubility data were obtained by adding $100 \mathrm{mg}$ of (-)-epicatechin in a sample holder in the equilibration column. The system was heated to a desired temperature $(313.15,323.15$, 333.15 , or $343.15 \mathrm{~K}$ ). Subsequently, liquid $\mathrm{CO}_{2}$ was pumped into the system using the high-pressure pump until a desired pressure was reached (12-26 MPa). After equilibrium condition was achieved in $4 \mathrm{~h}$ (insignificant increase of epicatechin concentration in $\mathrm{CO}_{2}$ was observed after $3 \mathrm{~h}$ ), the output valve was released, and the sample flowed into a collector containing a known amount of ethanol to separate epicatechin and $\mathrm{CO}_{2}$. At least three replications of trials were carried out for every set of temperature and pressure, and the equilibrium composition was represented by average of the three replications. The uncertainty of each measurement was within $\pm 2 \%$. The determination of epicatechin concentration in ethanol was based on the method of Zuo et al. [32] by using a HPLC (Jasco HPLC PU-2089 plus) with a UV-vis detector (UV-2077 plus).

\section{Results and discussion}

The experimental equilibrium solubility data of epicatechin and the result of calculated densities of supercritical $\mathrm{SC} \mathrm{CO}_{2}$ at various pressures and temperatures using the Stryjek and Vera [33] modification of the Peng-Robinson equation of state are reported

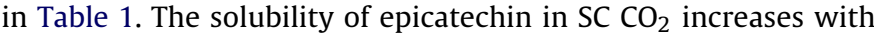
increasing pressure and temperature. At constant temperature, increasing pressure raises $\mathrm{SCCO}_{2}$ density and increases its ability to dissolve solute. At constant pressure, increasing temperature raises solute vapor pressure as well as the diffusivities of both solvent and solute.

The correlation of experimental solubility data was investigated using several semi-empirical models. Chrastil [30] proposed the first model for density-based correlation. It is based on the hypothesis that one molecule of a solute A associates with $k$ molecules of a solvent $\mathrm{B}$ to form one molecule of solvato-complex $A B_{k}$ in equilibrium with the system. The definition of the equilibrium constant through thermodynamic consideration resulted in the following model for the solubility:

$c_{1}=\rho^{k} \exp \left(\frac{a}{T}+b\right)$

where $c_{1}$ is the concentration of the solute in the gas $\left(\mathrm{gl}^{-1}\right), \rho$ is the density of the gas $\left(\mathrm{g}^{-1}\right), k$ is an association number, $a$ is a function of the enthalpy of solvation and enthalpy of vaporization $\left(\mathrm{K}^{-1}\right)$, and $b$ is a function of association number and molecular weights of the solute and supercritical fluids.

Various modifications on Chrastil model were proposed such as modified Chrastil by Garlapati and Madras [34,35], modified Chrastil by Wang [36], and modified Chrastil by del Valle and Aguilera [31]. Among these modified Chrastil models, del Valle and Aguilera [31] claimed that their model fitted well for temperatures from 293 to $353 \mathrm{~K}$ and pressure between 15 and $88 \mathrm{MPa}$ and adequately predicted solubility under $100 \mathrm{gl}^{-1}$ within the region suggested for commercial supercritical fluid extraction of food components (Eq. (2))

$c_{1}=\rho^{k^{\prime}} \exp \left(b^{\prime}+\frac{a^{\prime}}{T}+\frac{d}{r^{2}}\right)$

The physical meaning of the parameters $k^{\prime}, b^{\prime}$, and $a^{\prime}$ are similar to Chrastil model. The parameter $d^{\prime}$ is introduced to compensate the variation of enthalpy of vaporization ( $\left.\Delta H_{\mathrm{vap}}\right)$ with temperature.

Multivariable non-linear regression analysis of all experimental data was performed to estimate the constants in Chrastil model and modified Christil model by del Valle and Aguilera. The quality of all data correlations is quantified by the sum of squared errors (SSE), defined as follows:

$\operatorname{SSE}=\left(\frac{\left(\sum c_{1(\text { exp })}-c_{1(\text { cal })}\right)^{2}}{N}\right)^{1 / 2}$

where $c_{1(\exp )}$ is the actual solubility of epicatechin in $\mathrm{SC} \mathrm{CO}_{2}, c_{1(\mathrm{cal})}$ is the calculated solubility, and $N$ is the number of experimental data. Multivariable non-linear regression technique employed an iterative curve fitting procedure. An initial estimation for each parameter was provided, and then calculation of a point-by-point sum of squares (Eq. (3)) for each iteration was conducted until convergence criteria were fulfilled. 
Table 1

Solubility of epicatechin in $\mathrm{SCCO}_{2}$ and the $\mathrm{SCCO}_{2}$ density.

\begin{tabular}{|c|c|c|c|c|c|c|c|c|c|c|c|c|}
\hline \multirow[t]{2}{*}{$P(\mathrm{MPa})$} & \multicolumn{3}{|c|}{$T=313.15 \mathrm{~K}$} & \multicolumn{3}{|c|}{$T=323.15 \mathrm{~K}$} & \multicolumn{3}{|c|}{$T=333.15 \mathrm{~K}$} & \multicolumn{3}{|c|}{$T=343.15 \mathrm{~K}$} \\
\hline & $\rho\left(\mathrm{gl}^{-3}\right)$ & $10^{3} c_{1}\left(\mathrm{gl}^{-3}\right)$ & $10^{6} y^{a}$ & $\overline{\rho\left(\mathrm{gl}^{-3}\right)}$ & $10^{3} c_{1}\left(\mathrm{gl}^{-3}\right)$ & $10^{6} y^{\mathrm{a}}$ & $\rho\left(\mathrm{gl}^{-3}\right)$ & $10^{3} c_{1}\left(\mathrm{gl}^{-3}\right)$ & $10^{6} y^{a}$ & $\rho\left(\mathrm{gl}^{-3}\right)$ & $10^{3} c_{1}\left(\mathrm{gl}^{-3}\right)$ & $10^{6} y^{\mathrm{a}}$ \\
\hline 12 & 669 & $2.90 \pm 0.06$ & $0.66 \pm 0.014$ & 537 & $3.28 \pm 0.077$ & $0.93 \pm 0.022$ & 417 & $2.95 \pm 0.088$ & $1.09 \pm 0.032$ & 342 & $3.25 \pm 0.053$ & $1.49 \pm 0.024$ \\
\hline 13 & 701 & $3.56 \pm 0.10$ & $0.77 \pm 0.022$ & 588 & $4.51 \pm 0.136$ & $1.16 \pm 0.035$ & 474 & $5.07 \pm 0.136$ & $1.65 \pm 0.044$ & 390 & $5.64 \pm 0.152$ & $2.27 \pm 0.059$ \\
\hline 14 & 727 & $3.97 \pm 0.02$ & $0.83 \pm 0.004$ & 627 & $6.48 \pm 0.162$ & $1.57 \pm 0.039$ & 523 & $7.64 \pm 0.222$ & $2.27 \pm 0.064$ & 436 & $9.07 \pm 0.165$ & $3.26 \pm 0.057$ \\
\hline 15 & 750 & $4.40 \pm 0.12$ & $0.89 \pm 0.024$ & 659 & $7.83 \pm 0.196$ & $1.80 \pm 0.045$ & 563 & $9.85 \pm 0.207$ & $2.88 \pm 0.056$ & 478 & $13.90 \pm 0.160$ & $4.38 \pm 0.051$ \\
\hline 16 & 769 & $5.15 \pm 0.12$ & $1.02 \pm 0.024$ & 685 & $9.19 \pm 0.259$ & $2.03 \pm 0.057$ & 598 & $\begin{array}{r}14.25 \\
\pm 0.322\end{array}$ & $3.50 \pm 0.082$ & 515 & $19.91 \pm 0.358$ & $5.56 \pm 0.011$ \\
\hline 17 & 787 & $5.65 \pm 0.10$ & $1.09 \pm 0.019$ & 709 & $10.70 \pm 0.195$ & $2.290 \pm 0.042$ & 627 & $17.89 \pm 0.292$ & $4.09 \pm 0.071$ & 549 & $24.20 \pm 0.544$ & $6.85 \pm 0.015$ \\
\hline 18 & 803 & $6.02 \pm 0.18$ & $1.14 \pm 0.034$ & 729 & $11.50 \pm 0.129$ & $2.39 \pm 0.027$ & 653 & $20.10 \pm 0.308$ & $4.67 \pm 0.071$ & 578 & $30.01 \pm 0.430$ & $8.10 \pm 0.011$ \\
\hline 19 & 818 & $6.53 \pm 0.02$ & $1.21 \pm 0.004$ & 748 & $13.36 \pm 0.338$ & $2.72 \pm 0.068$ & 675 & $22.50 \pm 0.215$ & $5.19 \pm 0.048$ & 604 & $36.21 \pm 0.927$ & $9.34 \pm 0.023$ \\
\hline 20 & 831 & $6.97 \pm 0.03$ & $1.27 \pm 0.006$ & 765 & $14.10 \pm 0.229$ & $2.79 \pm 0.045$ & 696 & $25.70 \pm 0.402$ & $5.73 \pm 0.088$ & 628 & $44.78 \pm 0.961$ & $\begin{array}{r}10.57 \pm 0.023 \\
\end{array}$ \\
\hline 21 & 844 & $7.49 \pm 0.06$ & $1.34 \pm 0.011$ & 780 & $15.60 \pm 0.409$ & $3.03 \pm 0.079$ & 714 & $29.51 \pm 0.507$ & $6.22 \pm 0.108$ & 649 & $51.38 \pm 0.904$ & $11.77 \pm 0.021$ \\
\hline 22 & 856 & $8.01 \pm 0.03$ & $1.42 \pm 0.005$ & 794 & $17.08 \pm 0.482$ & $3.26 \pm 0.092$ & 732 & $32.01 \pm 0.465$ & $6.73 \pm 0.096$ & 669 & $57.96 \pm 0.569$ & $12.98 \pm 0.13$ \\
\hline 23 & 867 & $8.32 \pm 0.22$ & $1.46 \pm 0.038$ & 808 & $18.10 \pm 0.275$ & $3.40 \pm 0.052$ & 747 & $36.01 \pm 0.343$ & $7.18 \pm 0.070$ & 687 & $62.06 \pm 0.673$ & $14.14 \pm 0.015$ \\
\hline 24 & 877 & $8.87 \pm 0.09$ & $1.53 \pm 0.016$ & 820 & $19.50 \pm 0.316$ & $3.60 \pm 0.058$ & 762 & $38.05 \pm 0.474$ & $7.66 \pm 0.094$ & 704 & $70.15 \pm 0.635$ & $15.31 \pm 0.014$ \\
\hline 25 & 887 & $9.20 \pm 0.12$ & $1.57 \pm 0.021$ & 832 & $20.73 \pm 0.273$ & $3.77 \pm 0.050$ & 775 & $41.14 \pm 0.328$ & $8.10 \pm 0.064$ & 719 & $77.72 \pm 0.694$ & $16.38 \pm 0.015$ \\
\hline 26 & 896 & $9.68 \pm 0.08$ & $1.64 \pm 0.014$ & 843 & $21.82 \pm 0.203$ & $3.92 \pm 0.036$ & 788 & $44.92 \pm 0.263$ & $8.54 \pm 0.051$ & 734 & $85.86 \pm 0.673$ & $17.53 \pm 0.014$ \\
\hline
\end{tabular}

$y$ is mole fraction. The standard uncertainty is estimated using standard deviation of the mean:

$u\left(x_{i}\right)=\left(\frac{1}{n(n-1)} \sum_{k=1}^{n}\left(X_{i, k}-\bar{X}_{l}\right)^{2}\right)^{1 / 2}$
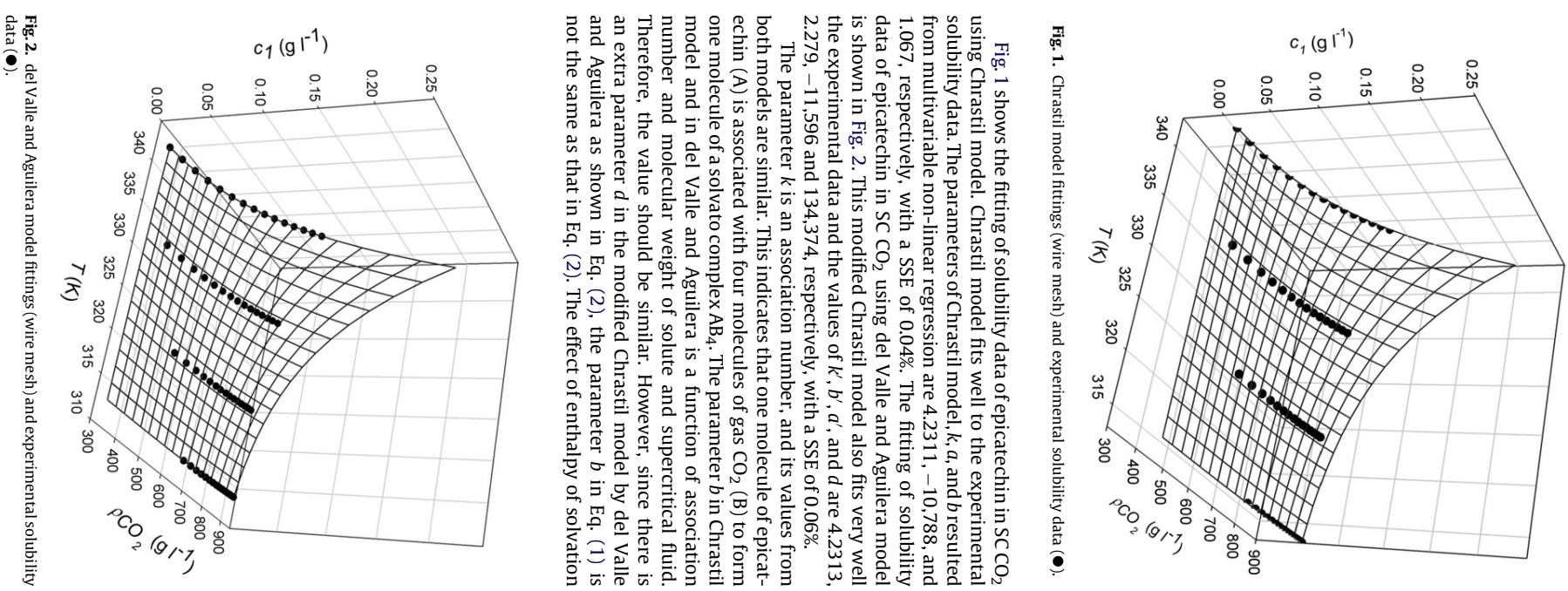


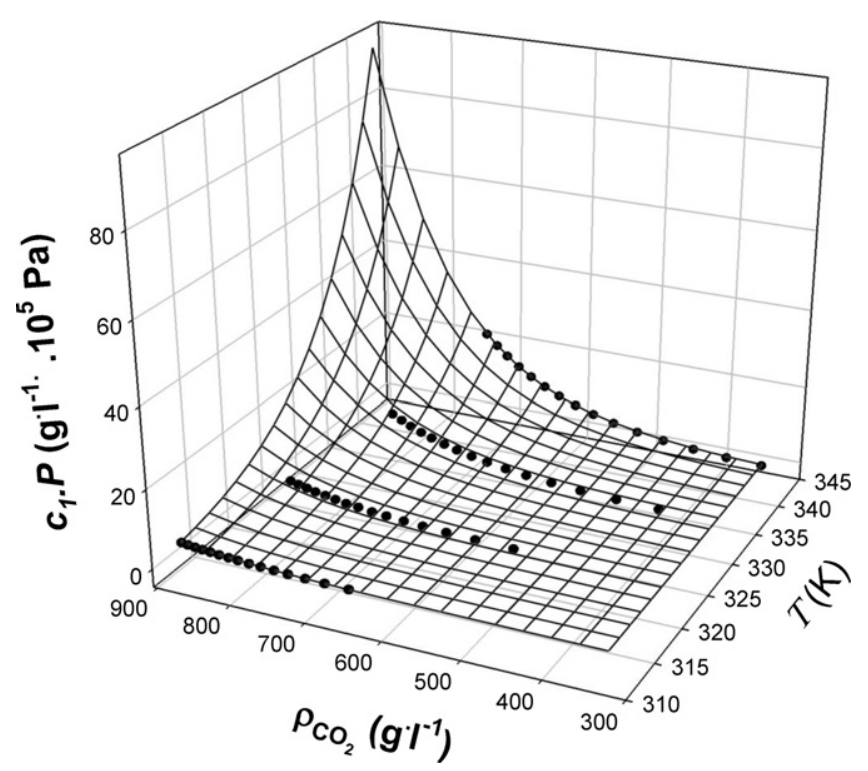

Fig. 3. Méndez-Santiago and Teja model fittings (wire mesh) and experimental solubility data $(\bullet)$.

and enthalpy of vaporization in Chrastil model is presented in the parameter $a(a=\Delta H / R)$. However, del Valle and Aguilera [31] modified this parameter to compensate the variation of enthalpy of vaporization with temperature $\left(\Delta H(T)=R\left(a^{\prime}+2 d / T\right)\right)$. The heat of solution $(\Delta H)$ for epicatechin and $\mathrm{CO}_{2}$ using Chrastil model is $89.7 \mathrm{~kJ} / \mathrm{mol}$, while using del Valle and Aguilera the heat of solution falls in a range of $87.3-89.9 \mathrm{~kJ} / \mathrm{mol}$. From the analyses of all parameters for both models, we conclude that the solubility of epicatechin in $\mathrm{SC} \mathrm{CO}_{2}$ can be well fitted by both models.

Another semi-empirical density based model was proposed by Méndez-Santiago and Teja [19] based on the theory of dilute solutions. This model took into account Henry's law, infinite dilution partition coefficients near the critical point of the solvent and Clausius-Clapeyron-type expression for the sublimation pressure. The equation has three adjustable parameters $\left(A^{\prime}, B^{\prime}\right.$ and $\left.C^{\prime}\right)$, defined as follow:

$T \ln \left(c_{1} P\right)=A^{\prime}+B^{\prime} \rho+C^{\prime} T$

Fig. 3 shows that the Méndez-Santiago and Teja model can represent the experimental solubility data of epicatechin in $\mathrm{SC} \mathrm{CO}_{2}$ well. Values of $A^{\prime}, B^{\prime}$ and $C^{\prime}$ are $-15,230,3.008$ and 4.108, respectively, and the SSE is $1.18 \%$. The three constants $\left(A^{\prime}, B^{\prime}\right.$ and $\left.C^{\prime}\right)$ are the result of multivariable non-linear regression analysis, which is independent of temperature and pressure without any significant physical meaning, therefore, can be used to extrapolate solubility data to other temperature [19].

\section{Conclusion}

Solubility data of epicatechin in $\mathrm{SC} \mathrm{CO}_{2}$, in wider ranges of temperature and pressure, were obtained in this study. The experimental data was fitted by using density-based models (Chrastil, del Valle and Aguilera and Méndez-Santiago and Teja). The models fitted very well to the experimental data and resulted in reasonable values of the fitting parameters.

\section{References}

[1] I. Ramirez-Sanchez, L. Maya, G. Ceballos, F. Villarreal, J. Food Compost. Anal. 23 (2010) 790-793.

[2] Y. Yilmaz, Food Sci. Technol.: LEB 17 (2006) 64-71.

[3] S. Sang, S. Tian, H. Wang, R.E. Stark, R.T. Rosen, C.S. Yang, C.-T. Ho, Bioorg. Med Chem. 11 (2003) 3371-3378.

[4] S. Sang, X. Cheng, R.E. Stark, R.T. Rosen, C.S. Yang, C.-T. Ho, Bioorg. Med. Chem. 10 (2002) 2233-2237.

[5] C. Passos, R.M. Silva, F.A. Da Silva, M.A. Coimbra, C.M. Silva, Chem. Eng. J. 160 (2010) 634-640.

[6] M. Palma, Z. Pineiro, C.G. Barroso, J. Chromatogr. A 968 (2002) 1-6.

[7] P. Lacopini, M. Baldi, P. Storchi, L. Sebastiani, J. Food Compost. Anal. 21 (2008) 589-598.

[8] S.M. Anthonysamy, N.B. Saari, K. Muhammad, F.A. Bakar, J. Food Biochem. 28 (2004) 91-99.

[9] J.S. Lee, S.U. Kang, H.S. Hwang, J.H. Pyun, Y.H. Choung, C.H. Kim, Toxicol. Lett. 199 (2010) 308-316.

[10] K. Matsubara, A. Saito, A. Tanaka, N. Nakajima, R. Akagi, M. Mori, Y. Mizushina, Life Sci. 80 (2007) 1578-1585.

[11] C. Lozano, J.L. Torres, L. Julia, A. Jimenez, J.J. Centelles, M. Cascante, FEBS Lett. 579 (2005) 4219-4225.

[12] S. Azam, N. Hadi, N.U. Khan, S.M. Hadi, Toxicol. in Vitro 18 (2004) 555-561.

[13] A. Liazid, M. Palma, J. Brigui, C.G. Barroso, J. Chromatogr. A 1140 (2007) 29-34

[14] K.N. Prasad, F.A. Hassan, B. Yang, K.W. Kong, R.N. Ramanan, A. Azlan, A. Ismail, Food Chem. 128 (2011) 1121-1127.

[15] M. Palma, Z. Pineiro, C.G. Barroso, J. Chromatogr. A 921 (2001) 169-174

[16] J.-L. Chen, C.-Y. Liu, Anal. Chim. Acta 528 (2005) 83-88.

[17] I. Ignat, I. Volf, V.I. Popa, Food Chem. 126 (2011) 1821-1835.

[18] Q. Song, J. Zhu, J. Wan, X. Cao, J. Chem. Eng. Data 55 (2010) 3946-3951.

[19] J. Méndez-Santiago, A.S. Teja, Fluid Phase Equilib. 158-160 (1999) 501-510.

[20] A. Chafer, T. Fornari, A. Berna, R.P. Stateva, J. Supercrit. Fluids 32 (2004) 89-96

[21] A. Berna, A. Chafer, J.B. Monton, S. Subirats, J. Supercrit. Fluids 20 (2001) 157-162.

[22] A. Chafer, A. Berna, J.B. Monton, R. Munoz, J. Supercrit. Fluids 24(2002)103-109.

[23] A.V.M. Nunes, A.A. Matias, M. Nunes da Ponte, C.M.M. Duarte, J. Chem. Eng. Data 52 (2007) 244-247.

[24] M.D.A. Saldana, B. Tomberli, S.E. Guigard, S. Goldman, C.G. Gray, F. Temelli, J. Supercrit. Fluids 40 (2007) 7-19.

[25] R. Murga, M.T. Sanz, S. Beltran, J.L. Cabezas, J. Supercrit. Fluids 27 (2003) 239-245.

[26] K. Suzuki, H. Sue, J. Chem. Eng. Data 35 (1990) 63-66.

27] C.-Y. Day, C.J. Chang, C.-Y. Chen, J. Chem. Eng. Data 41 (1996) 839-843.

[28] A. Braeuer, S. Dowy, A. Leipertz, R. Schatz, E. Schluecker, Opt. Express 15 (2007) 8377-8382.

[29] S.N. Joung, C.W. Yoo, H.Y. Shin, S.Y. Kim, K.-P. Yoo, C.S. Lee, W.S. Huh, Fluid Phase Equilib. 185 (2001) 219-230.

[30] J. Chrastil, J. Phys. Chem. 86 (1982) 3016-3021.

[31] J.M. del Valle, J.M. Aguilera, Ind. Eng. Chem. Res. 27 (1988) 1551-1553.

[32] Y. Zuo, H. Chen, Y. Deng, Talanta 57 (2002) 307-316.

[33] R. Stryjek, J.H. Vera, Can. J. Chem. Eng. 64 (1986) 323-333.

[34] C. Garlapati, G. Madras, J. Chem. Eng. Data 53 (2008) 2913-2917.

[35] C. Garlapati, G. Madras, J. Chem. Eng. Data 53 (2008) 2637-2641.

[36] M. Skerget, Z. Knez, M. Knez-Hrncic, J. Chem. Eng. Data 56 (2011) 694-719. 